\title{
Effect of an intervention aimed at reducing the risk of allergic respiratory disease in bakers: change in flour dust and fungal alpha-amylase levels
}

T Meijster, E Tielemans and D Heederik

Occup. Environ. Med. 2009;66;543-549; originally published online 13 Apr 2009; doi:10.1136/oem.2008.042564

Updated information and services can be found at:

http://oem.bmj.com/cgi/content/full/66/8/543

\section{These include:}

References This article cites 34 articles, 19 of which can be accessed free at: http://oem.bmj.com/cgi/content/full/66/8/543\#BIBL

Rapid responses

You can respond to this article at: http://oem.bmj.com/cgi/eletter-submit/66/8/543

Email alerting

Receive free email alerts when new articles cite this article - sign up in the box at the top right corner of the article

Notes

To order reprints of this article go to:

http://journals.bmj.com/cgi/reprintform

To subscribe to Occupational and Environmental Medicine go to:

http://journals.bmj.com/subscriptions/ 


\title{
Effect of an intervention aimed at reducing the risk of allergic respiratory disease in bakers: change in flour dust and fungal alpha-amylase levels
}

\author{
T Meijster, ${ }^{1,2}$ E Tielemans, ${ }^{1}$ D Heederik ${ }^{2}$
}

\begin{abstract}
${ }^{1}$ Department of Food and Chemical Risk Analysis, TNO Quality of Life, Zeist, The Netherlands; ${ }^{2}$ Division of Environmental Epidemiology, Institute for Risk Assessment Sciences, Utrecht University, Utrecht, The Netherlands
\end{abstract}

Correspondence to: Tim Meijster, TNO Quality of Life, Department of Food and Chemical Risk Analysis, Zeist, The Netherlands; tim.meijster@ tno.nl

Accepted 18 February 2009 Published Online First 13 April 2009

\begin{abstract}
Introduction: We evaluated the effect on exposure of an intervention programme, which focused on risk education and providing information on good work practices. This intervention programme was enrolled as part of a Dutch covenant in the flour processing industry (industrial bakeries, flour mills, ingredient producers).

Methods: Data from several measurement surveys collected pre- and post-intervention were used to evaluate changes in exposure over time. All datasets contained personal measurements analysed for flour dust and fungal $\alpha$-amylase contents, and contextual information was available on process characteristics, work practice, and use of control measures.
\end{abstract}

Results: Changes in exposure over time varied substantially between sectors and jobs. For bakeries a modest downward annual trend of $-2 \%$ was found for flour dust and $-8 \%$ for amylase. For flour mills the annual trend for flour dust was $-12 \%$; no significant trend was observed for amylase. For ingredient producers results were generally non-significant but indicated a reduction in flour dust exposure and increase in fungal $\alpha$-amylase exposure. Modest increase in use of control measures and proper work practices were reported in most sectors, especially the use of local exhaust ventilation and decreased use of compressed air.

Conclusions: The magnitude of the observed reductions in exposure levels indicates that the sector-wide intervention strategy implemented during the covenant period had a limited overall effect. This indicates that a more rigorous approach is needed to substantially decrease the exposure levels to flour dust and related allergens and, respectively, the prevalence of associated occupational diseases.

In many occupational settings exposure to hazardous substances has declined during the past decades. ${ }^{12}$ Most suggested reasons for this are the introduction of exposure limits and technological innovations in processes. ${ }^{3}{ }^{4}$ However, the specific mechanisms which explain observed time-related trends in exposure are poorly understood. ${ }^{5}$ Almost all studies on exposure trends involve the reanalyses of existing exposure data that often result in an inability to rigorously evaluate determinants of exposure. Studies that are a priori designed to evaluate changes in exposure levels across time are very rare. A notable exception is the Minnesota Wood Dust study. ${ }^{67}$ This study evaluated the effectiveness of tailored interventions on occupational exposure in small wood-working shops, using a group randomised trial. A comparison was made between a group of companies receiving an extensive intervention (training of workers, technical assistance and written recommendations) and a control group only receiving written recommendation. The results showed a lower than expected effect of the extensive intervention scheme, which was attributed to the challenges related to the implementation of interventions in small enterprises.

For the bakery sector and several other flour processing sectors no decline in exposure over time was reported in recent studies. ${ }^{3}$ This is an important observation since occupational exposure to flour dust is one of the most observed causes of occupational respiratory disease. ${ }^{910}$ In The Netherlands approximately 12000 workers perform work activities that have a high risk of exposure to flour dust and related allergens. ${ }^{11}{ }^{12}$ To significantly reduce occupational exposure to flour dust and related allergens, and decrease the prevalence of associated occupational disease, a sector-wide intervention programme was initiated in 2001.

This intervention programme was implemented as part of a covenant among social partners and major flour processing industries (bakeries, flour mills and ingredient producers). The social partners of the covenant were responsible for the design and conduct of the intervention programme. In The Netherlands, covenants can comprise detailed agreements to reduce exposures, introduce exposure control measures, or inform and educate workers. In the context of these covenants effectiveness of implemented control measures receives special attention. Various covenants in different sectors have been initiated in The Netherlands. An assessment of the impact of a covenant for hospitals in The Netherlands has been described elsewhere. $^{13}$

The main aim of the covenant in the major flour processing sectors was reduction of the burden of occupational respiratory diseases among workers exposed to flour dust. Workers' health was monitored through the instalment of a sector-wide health surveillance system. One of the major initiatives within the covenant intervention programme was to inform all employers and employees on the risks of occupational exposure(s) and provide information on good work practices and control measures. This campaign included visits to all companies by a trained consultant and the distribution of a dust control manual specifically developed for this purpose. ${ }^{14}$ This manual primarily contained information on practical control measures and work practices that are easy to implement and a limited number of more elaborate 
technological control measures. The content was primarily based upon general knowledge of potential control measures and lacked a sound scientific evidence base. The manual also included a dust control plan that every company had to fill in to obtain an overview of the current state of dust control and the plans and possibilities for future improvements. Within the covenant, specific aims were set with respect to exposure reduction, that is, all sectors committed to a $50 \%$ reduction in time-weighted average exposure levels for flour dust and ingredient producers also aimed at a $50 \%$ reduction for fungal $\alpha$-amylase.

To evaluate the impact of the covenant on occupational exposure levels, surveys were performed in all three sectors, both at the beginning and at the end of the covenant period. This article describes the evaluation of time-related trends in occupational exposure. The results are discussed in light of observed changes in work characteristics and use of control measures.

The presented study is one in a series of studies focusing on potential exposure reductions and their health impact in flour processing industries. The results of the time trend evaluation will be used as a baseline scenario in a health impact assessment study focusing on the population burden of disease in the flour processing industry in The Netherlands. The collated information may also provide information on potential further actions that need to be undertaken to increase awareness of risk and stimulate control of occupational exposure.

\section{MATERIALS AND METHODS}

\section{Exposure data}

A large database was created using two large-scale and three small-scale exposure assessment surveys which have been conducted during the covenant period. The covenants' baseline exposure survey, which led to agreements regarding exposure reduction included in the covenant, was performed in the three major flour processing sectors (bakeries, flour mills and ingredient producers) in 2001, and included 638 personal exposure measurements. This study is described in detail by Meijster et al. ${ }^{8}$ At the end of the covenant period, in 2007, another large survey was performed to evaluate the effect of the covenant. Where possible this survey included the same companies and workers as the baseline study in 2001. Traditional bakeries were not included in this survey. This study comprised 310 personal exposure measurements. The three small exposure surveys conducted during the covenant comprised a total of 272 personal exposure measurements. These studies were performed in 2005 and included measurements from traditional bakeries, industrial bakeries and flour mills.

For the bakery sector the exposure component of an epidemiological study, performed in the early nineties, focusing on occupational exposure in relation to respiratory symptoms was also included in the analysis. ${ }^{15} 16$ This study comprised 550 personal exposure measurements obtained from a random sample of workers in both traditional and industrial bakeries. The final dataset comprised 1770 personal exposure measurements generally including data on flour dust and fungal $\alpha$-amylase levels for most samples. Table 1 gives descriptive statistics and references for the different datasets used in the analyses.

\section{Exposure assessment}

In all surveys personal sampling was performed in the breathing zone of the worker. Full shift samples were obtained. During the post-intervention survey, workers sampled during earlier surveys were preferentially included. If this was not possible,
Table 1 Descriptive statistics and references for the different datasets used in the analyses

\begin{tabular}{|c|c|c|c|c|c|c|c|}
\hline \multirow[b]{2}{*}{$\begin{array}{l}\text { Study } \\
\text { period }\end{array}$} & \multirow[b]{2}{*}{$\mathrm{n}$} & \multirow[b]{2}{*}{ k } & \multirow[b]{2}{*}{ c } & \multicolumn{3}{|l|}{ Sectors } & \multirow[b]{2}{*}{ References } \\
\hline & & & & Bakeries & $\begin{array}{l}\text { Flour } \\
\text { mills }\end{array}$ & $\begin{array}{l}\text { Ingredient } \\
\text { producers }\end{array}$ & \\
\hline 1993 & 550 & 180 & 21 & 550 & - & - & 151638 з9 \\
\hline 2001 & 638 & 99 & 95 & 356 & 156 & 126 & 8 \\
\hline 2005 & 272 & 86 & 24 & 225 & 47 & - & 8 \\
\hline 2007 & 310 & 67 & 23 & 131 & 88 & 91 & - \\
\hline Total & 1770 & & & 1262 & 291 & 217 & \\
\hline
\end{tabular}

c, number of companies; k, number of workers with repeated measurements; $n$, total number of samples.

workers with a similar job title and task pattern were included. Measurement duration was between 4 and $10 \mathrm{~h}$ with $85 \%$ of samples having more than $6 \mathrm{~h}$ of sampling time. All personal air samples were obtained using a PAS6 sampling head (Wageningen University, Wageningen, The Netherlands), with a mounted glass fibre filter, connected to a Gillian GilAir sampling pump (Sensidyne Gillian, Clearwater, USA) with a calibrated air flow of $2 \mathrm{l} / \mathrm{min}$. Dust levels on the filters were determined by pre- and post-sampling weighing of the filters after conditioning them for $24 \mathrm{~h}$ in an acclimatised room. Details on personal air sampling can be found in Meijster et al. ${ }^{8}$ After determining the dust weight, samples were extracted and analysed for their contents of fungal $\alpha$-amylase using immunoassays. For all studies similar extraction and analyses techniques were used. These analyses and extracting procedures are described in detail by Houba et al ${ }^{16}$ and Bogdanovic et al. ${ }^{17}$

\section{Contextual data}

Contextual data were obtained from two sources. Information on process characteristics, work practice, and use of control measures was obtained in a walk-through survey conducted during the measurement surveys by a trained field worker. We also obtained the dust control plans that were part of the dust control manual of all companies involved in the post-covenant study. This provided a more general overview of recent and future changes in these companies, especially with respect to implementation of control measures. Additionally, a limited survey was performed in a small sample of companies from all sectors to look at the impact of the covenant with respect to familiarity of bakery workers with the risk of flour dust and their knowledge of potential control measures. This survey also identified how many bakeries received the dust control manual and filled in a dust control plan.

The quality and nature of the obtained information varied substantially between the different studies. In some surveys information was very detailed and gathered for individual workers; in other surveys information was only obtained on company level or in a qualitative way (eg, description of changes in retrospect). In some cases definitions of variables changed in between studies initiated by insights obtained in prior studies. Where possible, changes in process characteristics, work practice and use of control measures were evaluated in a quantitative manner preferably on worker level and otherwise on company level. If data did not allow for such analysis a qualitative description of the changes is presented to give an overview of the interventions that resulted from the covenant.

\section{Statistical analysis}

The distribution of the exposure data was determined to be approximately log-normal using fit tests and visual inspection 
of plots of the data. Descriptive statistics (arithmetic and geometric mean, geometric standard deviation and range) were calculated for both flour dust and fungal $\alpha$-amylase stratified for sector and time period. Box plots of both flour dust and fungal $\alpha$-amylase levels were created stratified for sector and study year. Evaluation of exposure trends was performed with linear mixed-effects models using the Proc Mixed procedure in SAS (version 9). Separate time trend analyses were performed for the three sectors, that is, bakeries, flour mills and ingredient producers.

Changes in exposure levels over time were modelled by introducing year as a continuous variable in our mixed-effects models to estimate the annual relative change in average exposure. ${ }^{18}$ Job title and sampling duration were introduced in the models as co-variable to correct for possible confounding effects. Sampling duration was introduced as a continuous variable. Co-variables were included in the final models if the maximum likelihood test showed significant improvement of model fit $(p<0.05)$.

Worker and company were incorporated into the analysis as random-effect variables to account for correlation in the exposure data. ${ }^{19}$ Significance of random-effect variables was tested after adding co-variables (fixed effects). If random effects were not significant they were excluded from the final analysis. A compound symmetric covariance structure was assumed. The models were evaluated for heteroscedasticity using residual plots. Time trend models stratified for job (eg, bread bakers, general bakers, pastry bakers, dough makers and low-exposed jobs) were used to evaluate trends in exposure levels in more detail. Final analyses were performed looking at trends for the total time period for which data were available. For bakeries, separate analyses were performed for the covenant period only (ie, 2001-2007) to look at effects of intervention implemented specifically during this period.

\section{RESULTS}

The survey measuring the familiarity of bakery workers with the health risks revealed that $>70 \%$ of workers were familiar with the risk of flour dust exposure. Only 35\% of traditional bakeries reported to be familiar with the dust control manual. This was higher for the other sectors (between 50 and 100\%). Only $30 \%$ of the traditional bakeries filled in a dust control plan (between 48 and 100\% for the other sectors). This means that although the information on risk did reach the workers the actual implementation of the main tools provided was limited especially in the traditional bakeries that represent $>60 \%$ of the worker population. ${ }^{20}$

A similar picture arises from the contextual data obtained in the measurement studies. In the post-covenant study 23 companies were eventually visited; 21 of these companies were also visited in the baseline exposure survey (2001). The matching of workers was not successful due to high turnover. As an alternative, we were able to match measurements on job title within a company.

The information from the walk-through survey showed that for several control measures a clear increase in use occurred. The most significant increase was observed in the use of local exhaust ventilation (LEV). In the pre-covenant period the use of LEV was negligible in both flour mills and industrial bakeries, whereas after the covenant period use of LEV was reported by approximately $40 \%$ of workers in industrial bakeries and $60 \%$ of workers in flour mills. For ingredient production LEV was already common and it further increased during the intervention from $57 \%$ to $70 \%$. In bakeries LEV was mainly installed at flour dumping installations, often combined with (partial) enclosure of the mixing tub. For flour mills and ingredient production industry LEV was mainly installed at bagging and ingredient dumping sites as well as weighing locations.

Use of pressured air is an important factor for (peak) exposures; unfortunately this variable was only obtained in a very crude way in the pre-covenant study. In general, the dust control plans reported for many companies that use of compressed air was replaced with use of vacuum cleaning. However observational data from the post-covenant survey showed that $51 \%, 64 \%$ and $42 \%$ of workers still reported the use of compressed air in bakeries, flour mills and ingredient producers, respectively.

In bakeries the use of liquid instead of powder bread improver (containing fungal $\alpha$-amylase) increased from $30 \%$ to $50 \%$ of workers involved in dough production. Other important factors, especially related to work practice, were not evaluated in a quantitative manner. The results of the post-covenant study did suggest more attention is paid in general to dust-free work practice, for example, not shaking bags when dumping flour and/or additives, use of wet cleaning methods instead of sweeping, and a decrease in the use of dusting flour were often mentioned by the companies as implemented interventions.

Figure 1 shows the box plots of the overall trends in exposure not corrected for any co-variables. The plots do not show any clear changes in exposure over time for flour dust for any of the sectors. For fungal $\alpha$-amylase the plot indicates a slight downward trend for bakeries. In flour mills and ingredient producers this is less obvious; for the latter one the plot clearly indicates an increase of exposure over time.

In the overall models for each sector, job was included as a covariable to account for possible selection effects in the various time periods. Sample time had a significant effect in only two job-specific models, and was excluded from other analyses. For the sector-specific analyses both worker and company random effects were statistically significant and were kept in the models. The company random effect was not significant in any of the job-specific trend models, whereas the worker random effect was significant. Table 2 gives the overall yearly trends for all three sectors and the trends stratified by job title. A significant yearly downward trend of approximately $2 \%$ was observed for flour dust and $8 \%$ for fungal $\alpha$-amylase among the population of bakery workers. Trends varied substantially between job categories. Dough makers, general bakers, cleaners and maintenance workers showed a statistically significant downward trend for exposure to flour dust. No clear time trend was observed for the other jobs. For fungal $\alpha$-amylase a statistically significant downward trend was observed for pastry bakers and cleaners. For general bakers a strong increasing trend in exposure to $\alpha$-amylase was observed ( $>20 \%$ yearly), whereas trends were absent for bread bakers, dough makers, maintenance workers and low-exposed jobs. Stratified analysis only looking at the data for the covenant period (ie, 2001-2007) showed similar overall trend patterns.

In flour mills a strong decreasing exposure trend of $12 \%$ annually was observed for flour dust. This downward trend for flour dust was observed for almost all job categories (although not significant in most instances). Conversely, fungal $\alpha$-amylase results indicate that an overall time trend was absent. On job levels a significant decreasing trend was only observed in maintenance workers.

For workers in ingredient production an overall downward trend in flour dust exposure was not significant. Stratified analyses showed inconsistent results with non-significant 

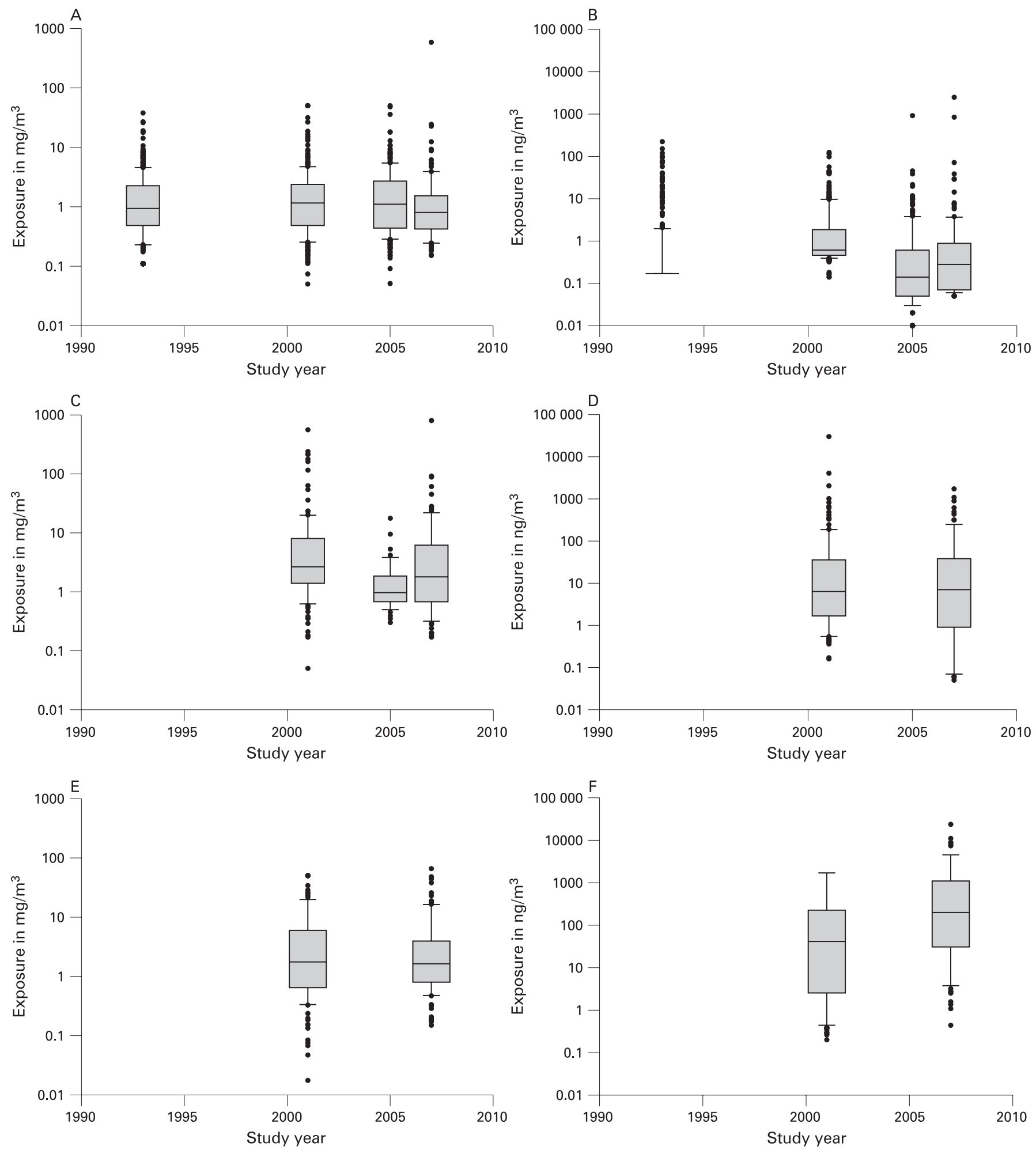

Figure 1 (A) Time trend in flour dust exposure for the total measured populations of bakery workers. (B) Time trend in fungal $\alpha$-amylase exposure for the total measured populations of bakery workers. (C) Time trend in flour dust exposure for the total measured populations of flour mill workers. (D) Time trend in fungal $\alpha$-amylase exposure for the total measured populations of flour mill workers. (E) Time trend in flour dust exposure for the total measured populations of ingredient production workers. (F) Time trend in fungal $\alpha$-amylase exposure for the total measured populations of ingredient production workers.

increasing and decreasing exposure levels for various job titles. For fungal $\alpha$-amylase there has been a strong increase in occupational exposure for all job titles. Overall a non-significant increasing exposure trend of almost 30\% annually was observed for the covenant period.

\section{DISCUSSION}

This study evaluated the impact of an intervention programme implemented in several Dutch flour processing sectors, as part of a covenant. Moderate decreasing exposure trends were observed for flour dust and amylase in bakeries and for flour 
Table 2 Yearly trends in flour dust and fungal $\alpha$-amylase exposure between 1993 and 2007, stratified for sector

\begin{tabular}{|c|c|c|c|c|c|c|c|}
\hline \multirow[b]{2}{*}{ Sector } & \multirow[b]{2}{*}{ Function } & \multicolumn{3}{|l|}{ Dust } & \multicolumn{3}{|c|}{ Fungal $\alpha$-amylase } \\
\hline & & No* & $\begin{array}{l}\text { Trend } \\
\text { (\%/year) }\end{array}$ & $\begin{array}{l}\text { Significance } \\
\text { (p value) }\end{array}$ & No* & $\begin{array}{l}\begin{array}{l}\text { Trend } \\
\text { (\%/year) }\end{array}\end{array}$ & $\begin{array}{l}\text { Significance } \\
\text { (p value) }\end{array}$ \\
\hline \multirow{8}{*}{$\begin{array}{l}\text { Bakeries§ } \\
\text { (1993-2007) }\end{array}$} & & 1259 & -1.9 & 0.08 & 1149 & -8.2 & 0.00 \\
\hline & Bread bakers & 305 & 0.8 & 0.57 & 281 & 3.0 & 0.23 \\
\hline & Dough makers $\dagger$ & 233 & -4.0 & 0.00 & 221 & -0.0 & 0.90 \\
\hline & Pastry bakers & 104 & 4.0 & 0.18 & 87 & -10.0 & 0.01 \\
\hline & General bakert & 122 & -3.6 & 0.00 & 109 & 20.4 & 0.00 \\
\hline & Cleaners $\uparrow$ & 46 & -3.7 & 0.02 & 43 & -4.8 & 0.08 \\
\hline & Maintenance workers & 30 & -21.2 & 0.02 & 29 & -16.0 & 0.10 \\
\hline & Low-exposed jobs & 407 & 0.0 & 0.94 & 379 & -1.3 & 0.29 \\
\hline \multirow{9}{*}{$\begin{array}{l}\text { Flour mills§ } \\
(2001-2007)\end{array}$} & & 291 & -11.9 & 0.01 & 230 & -3.3 & 0.81 \\
\hline & Miller & 39 & -11.3 & 0.33 & 32 & -14.4 & 0.45 \\
\hline & Baggers & 22 & -10.7 & 0.26 & 16 & -1.9 & 0.93 \\
\hline & Cleaners & 32 & -11.5 & 0.27 & 25 & 14.3 & 0.47 \\
\hline & Storage workers & 27 & -16.0 & 0.23 & - & - & - \\
\hline & General operators & 33 & -7.2 & 0.44 & 19 & -20.4 & 0.33 \\
\hline & Quality controllers & 31 & -14.7 & 0.03 & 26 & -8.6 & 0.56 \\
\hline & Maintenance worker & 47 & -10.6 & 0.01 & 41 & -20.7 & 0.01 \\
\hline & Chef & 29 & 0.4 & 0.97 & 28 & -13.6 & 0.33 \\
\hline \multirow{8}{*}{$\begin{array}{l}\text { Ingredient } \\
\text { producers§ } \\
\text { (2001-2007) }\end{array}$} & & 217 & -6.1 & 0.42 & 202 & 28.5 & 0.16 \\
\hline & Quality controllers & 25 & -9.9 & 0.25 & 22 & 31.8 & 0.15 \\
\hline & Chef & 15 & 26.5 & 0.20 & 15 & 66.5 & 0.12 \\
\hline & Weigher/mixer & 12 & -22.3 & 0.06 & 11 & 76.9 & 0.04 \\
\hline & Bagger & 38 & 4.2 & 0.63 & 37 & 56.6 & 0.01 \\
\hline & Storage worker & 31 & 10.7 & 0.29 & 29 & 17.7 & 0.24 \\
\hline & General operator & 30 & 0.8 & 0.93 & 15 & 16.5 & 0.38 \\
\hline & Dumper & 31 & -1.6 & 0.82 & 30 & 3.2 & 0.85 \\
\hline
\end{tabular}

Results are based on mixed-effects regression models with time period and job as fixed effects and company and worker as random effects. Bold values are significant at the $p<0.10$ level.

${ }^{*}$ Number of samples used in the analysis. †Only in industrial bakeries. $\$$ Only in traditional bakeries. §Only jobs with $>5$ samples in both measurement studies were evaluated. $\uparrow$ Corrected for sampling time.

dust in flour mills. However, a significant trend was absent for amylase in flour mills and for both flour dust and amylase in ingredient producers. In bakeries the observed time-related trends in exposure are strongest in workers involved in production and cleaning/maintenance activities. Attention focused on these activities during the covenant. In addition a recent study showed a substantial potential effect of a range of control measures, especially during production and processing of dough. ${ }^{21}$ For flour mills, the observed trend in flour dust exposure is comparable with trends in inhalable dust exposure in several other industrial environments. ${ }^{18} 2223$ An important difference with bakeries was the strict implementation of the covenant in each individual flour mill. The number of production facilities is limited and implementation of the covenant was centralised, resulting in a higher percentage of workers being informed and a better implementation of control measures. In the ingredient sector the reported trends fluctuated strongly between jobs. It seems that the (limited) additional measures taken in the covenant period had no significant effect on exposure to flour dust. For fungal $\alpha$-amylase it is unclear how exposure could have increased. Information from the sector did not indicate an increased use and no obvious changes in the work practice occurred. In general, for this sector the available data per job were limited and therefore trend estimates should be interpreted with caution.
Specific data quantifying the impact of control measures on exposure to fungal $\boldsymbol{\alpha}$-amylase are not available. It is likely that the observed changes in exposure for a large part can be attributed to the same control measures as for flour dust. The increased use of liquid enzyme-containing bread improver instead of powder form may have further decreased exposure in bakeries. Finally, recent literature indicates that in some cases fungal $\alpha$-amylase is replaced with other fungal enzymes. ${ }^{24}{ }^{25}$ The magnitude at which this occurs in the Dutch flour processing industries is unknown.

As this study shows, observed exposure trends may vary substantially between sectors and jobs and for different types of exposure. Therefore, if possible, analyses of exposure trends should be stratified for sectors and jobs, and different compounds should be evaluated separately when dealing with exposure to mixtures in order to detect subtle effects. However, associating these (subtle) changes in exposure with specific interventions or changes in work practice will generally remain difficult. An important reason for this is that a variety of changes in different exposure determinants is probably responsible for the relatively small changes in exposure. As a result it is also difficult to completely explain observed differences in exposure trends between jobs and sectors in light of this intervention programme.

Although information on wheat allergens exposure was also available from the different measurement studies, this was not 
taken into account in the analyses. The most important reason for the exclusion is the large yearly variation in wheat protein levels in grains based upon exogenous factors such as weather conditions, production soil, etc. ${ }^{26} 27$ To accurately perform trend analysis these exogenous factors should be taken into account and data to do so were not available.

The questionnaire data obtained in the post-covenant study indicated a substantial increase in awareness of risk among workers. The familiarity with the dust control manual and respectively the implementation of good work practice remained fairly limited, especially in the bakery sector. Where changes were observed the overall impact on exposure levels seems limited and could generally not be directly associated with specific changes in the workplace. This is in line with the observation that familiarity with the dust control manual was limited, especially in traditional bakeries. This study shows that when evaluating the impact of complex intervention strategies the quality of the contextual data to a large extent determines the possibility to evaluate detailed association between control measures and changes in exposure. The power of an intervention study will benefit immensely from using a strict design that approaches a true scientific experiment, preferably a randomised controlled trial design. ${ }^{78} 29$ However, in our study where a complete occupational population is the subject of an intervention programme, such a study will not be possible since a control population is not available. In these situations nonexperimental longitudinal data as presented in this study, might be the next best choice, even though many factors will be beyond the influence of the researcher (eg, drop out of companies/workers). Although we were able to match the majority of companies in the pre- and post-intervention study, we were only to a very limited extent able to trace the same workers in 2007 . This is primarily caused by the relatively long follow-up time (6-7 years) and the substantial turnover of workers in most branches. On the other hand a shorter followup time would have strongly decreased the implementation of control measures, which would have prohibited a comprehensive evaluation as well.

Exposure trend analyses have been performed in recent years for a large range of occupational exposures and environments. The main conclusion from many of these trend analyses is that occupational exposure has been decreasing in the past decades. ${ }^{124}$ Downward exposure trends of up to $12 \%$ annually are not uncommon; trends of between -5 and $-8 \%$ annually were most commonly observed.

It is likely that changes in exposure do not occur gradually but in a stepwise manner, either in relatively large steps associated with changes in legislation, elimination of exposure sources or other major changes in work characteristics, or in a combination of smaller steps associated with several relatively minor changes in the work characteristics. ${ }^{1530}$ In most cases, specific data to underpin this pattern of exposure change are lacking as are data to determine the relation with specific changes in determinants of exposure. ${ }^{12}$ Several studies that found downward trends in occupational exposure were to some extent able to identify determinants likely associated with exposure, but could generally not quantify their individual contribution to the observed exposure trends. ${ }^{31-35}$ A study by Vermeulen and co-authors in 2000 in the rubber producing industry showed a decreasing trend in exposure to inhalable particles and dermal exposure to cyclohexane soluble matter of $6-7 \%$ annually. They were able to relate different types of control measures and specific changes in work characteristics to changes in exposure over time. ${ }^{22}$

\section{Main messages}

- Only limited effect on exposure levels was observed from a sector-wide intervention programme in Dutch bakeries aimed primarily at education of workers.

- Although workers' knowledge on the risk of flour dust exposure improved, this only to a very limited extent resulted in change in work practice.

- This study shows that when evaluating the impact of complex intervention strategies the quality of the contextual data to a large extent determines the possibility to evaluate detailed association between control measures and changes in exposure.

\section{Policy implications}

- These results of this study indicate that a much more rigorous approach is needed to effectively decrease exposures in complex worker environments, especially when dealing with small- and medium-sized enterprises.

- The power of intervention studies will benefit immensely from using a strict design that approaches a true scientific experiment, preferably a randomised controlled trial design.

An important reason for the absence of a substantial overall time-related trend in exposure is the limited evidence base that underlies the content of the intervention programme, especially the dust control manual. The design was primarily determined by the social partners of the covenant with only very limited input from research(ers). This resulted in an approach that focused on education and training. The actual implementation of control measures was largely left to the responsibility of the employers (individual companies). This resulted in a limited amount of companies actually introducing controls within the covenant period. There are likely two important reasons for this; first, a limited motivation to change work practices. This lack of motivation is likely associated with a still relatively low risk awareness related to occupational exposure among bakery workers and the absence of exposure limits. The post-intervention study discloses that there is still a substantial group of workers that ignores the risks and continues to work in a way that potentially leads to high (peak) exposure levels. Second, there is limited technological advancement especially in bakeries. Financial constraints in small- and medium-sized enterprises may have limited the introduction of more advanced (control) technologies. In small bakeries in particular, the production processes still include a substantial amount of manual labour with many peak exposure moments. ${ }^{21}$ This might also explain why, for example, the increased use of LEV only had a minor effect. LEV is only used in a limited part of the work activities and in these cases it should be used appropriately to benefit fully. Furthermore a substantial group of companies, especially in the small traditional bakeries, did not, or only to a limited extent, participate in the activities initiated by the covenant. ${ }^{12}$

The fact that the intervention scheme implemented within the covenant period did not result in a more drastic overall exposure reduction is clearly disappointing. For bakeries this is 
specifically shown by the fact that the covenant did not result in a substantially larger change in exposure than what was observed in the period prior to the covenant (1993-2001). Earlier examples also show a limited effectiveness of large-scale intervention strategies among a broad worker population. ${ }^{67}$ These results indicate that a much more rigorous approach is needed to effectively decrease exposures in complex worker environments, especially when dealing with small- and medium-sized enterprises. Although no design for such a rigorous approach is readily available, it is likely that tailored workplace interventions aimed at (individual) workers within an identified high-risk population (eg, high exposed workers) might prove to be more effective.

Results from this study provide insight into the trends of exposure resulting from an intervention programme implemented in the recent Dutch covenant in the flour processing industry. Given the available dose-response information a limited reduction of the health risk is expected, with small differences between sectors. ${ }^{36}{ }^{37}$ More insight into the expected health impact of the observed changes in exposure will be provided by a recently performed health impact assessment using a recently developed dynamic population-based model. The results of this analysis may learn to what extent the observed (limited) decline in exposures will lead to an improvement of the health status in the population. This health impact assessment will also provide detailed information on exposure reductions that are required to arrive at a proportion of workers with health problems, which is more acceptable to all parties involved.

Acknowledgements: We want to thank all companies and workers who participated in the different exposure surveys.

Funding: Part of this study was financially supported by the Dutch Ministry of Social Affairs and Employment.

\section{Competing interests: None.}

\section{REFERENCES}

1. Creely KS, Cowie H, van Tongeren MJ, et al. Trends in inhalation exposure-a review of the data in the published scientific literature. Ann Occup Hyg 2007;51:665-78.

2. Symanski E, Kupper LL, Rappaport SM. Comprehensive evaluation of long-term trends in occupational exposure: Part 1. Description of the database. Occup Environ Med 1998;55:300-9.

3. Creely K, Tongeren van M, While D, et al. Trends in inhalation exposure: mid 1980 s till present. Suffolk: HSE Books, 2006.

4. Symanski E, Kupper LL, Hertz-Picciotto I, et al. Comprehensive evaluation of longterm trends in occupational exposure: Part 2. Predictive models for declining exposures. Occup Environ Med 1998;55:310-16.

5. Kromhout H, Vermeulen R. Long-term trends in occupational exposure: Are they real? What causes them? What shall we do with them? Ann Occup Hyg 2000:44:325-7.

6. Lazovich D, Parker DL, Brosseau LM, et al. Effectiveness of a worksite intervention to reduce an occupational exposure: the Minnesota wood dust study. Am J Public Health 2002;92:1498-505.

7. Brosseau LM, Parker DL, Lazovich D, et al. Designing intervention effectiveness studies for occupational health and safety: The Minnesota Wood Dust Study. Am J Ind Med 2002:41:54-61.

8. Meijster T, Tielemans E, de Pater N, et al. Modelling exposure in flour processing sectors in The Netherlands: a baseline measurement in the context of an intervention program. Ann Occup Hyg 2007;51:293-304.

9. Kogevinas M, Anto JM, Sunyer J, et al. Occupational asthma in Europe and other industrialised areas: a population-based study. European Community Respiratory Health Survey Study Group. Lancet 1999;353:1750-4.

10. Baur X, Degens PO, Sander I. Baker's asthma: still among the most frequent occupational respiratory disorders. J Allergy Clin Immunol 1998;102:984-97.
11. Health Council of the Netherlands. Dutch Expert Committee on Occupational Standards. Wheat and other cereal flour dusts. The Hague, The Netherlands: Health Council of the Netherlands (publication no. 2004/020SH), 2004.

12. Meijer E, Suarthana E, de Monchy J, et al. Diagnostic research in occupational allergy: Results of a nationwide surveillance among bakery workers. In: Suarthana E, ed. Predicting occupational lung disease. Utrecht, The Netherlands: Utrecht University, 2008: 89-101.

13. Meijster T, Fransman W, van Hemmen JJ, et al. A probabilistic assessment of the impact of interventions on oncology nurses' exposure to antineoplastic agents. Occup Environ Med 2006;63:530-7.

14. Goede H, Links I, Tielemans E, et al. Handboek Stofbeheersing. 2004. Online publication. http://www.Blijmetstofvrij.nl (accessed 30 May 2009).

15. Houba R, van Run P, Heederik D, et al. Wheat antigen exposure assessment for epidemiological studies in bakeries using personal dust sampling and inhibition ELISA. Clin Exp Allergy 1996;26:154-63.

16. Houba R, van Run P, Doekes G, et al. Airborne levels of alpha-amylase allergens in bakeries. J Allergy Clin Immunol 1997;99:286-92.

17. Bogdanovic J, Koets M, Sander I, et al. Rapid detection of fungal alpha-amylase in the work environment with a lateral flow immunoassay. J Allergy Clin Immunol 2006;118:1157-63.

18. de Vocht F, Vermeulen R, Burstyn I, et al. Exposure to inhalable dust and its cyclohexane soluble fraction since 1970s in the rubber manufacturing industry in the European Union. Occup Environ Med 2007:65:384-91.

19. Symanski E, Chan W, Chang C-C. Mixed-effects models for the evaluation of longterm trends in exposure levels with example from the nickel industry. Ann Occup Hyg 2001;:45:71-81.

20. Burau Bartels BV. Covenant ingredient allergy; final evaluation [report in Dutch]. The Hague: Ministry of Social Affairs and Employment, 2007.

21. Meijster T, Tielemans E, Schinkel J, et al. Evaluation of peak exposures in the Dutch flour processing industry: implications for intervention strategies. Ann Occup Hyg 2008;52:587-96.

22. Vermeulen R, de Hartog J, Swuste P, et al. Trends in exposure to inhalable particulate and dermal contamination in the rubber manufacturing industry: effectiveness of control measures implemented over a nine-year period. Ann Occup Hyg 2000;44:343-54.

23. van Tongeren MJ, Kromhout $H$, Gardiner $K$. Trends in levels of inhalable dust exposure, exceedance and overexposure in the European carbon black manufacturing industry. Ann Occup Hyg 2000;44:271-80.

24. Baur X, Sander I, Posch A, et al. Baker's asthma due to the enzyme xylanase - a new occupational allergen. Clin Exp Allergy 1998;28:1591-3.

25. Elms J, Fishwick D, Walker J, et al. Prevalence of sensitisation to cellulase and xylanase in bakery workers. Occup Environ Med 2003;60:802-4.

26. Payne PI. Genetics of wheat storage proteins and the effect of allelic variation on bread-making quality. Ann Rev Plant Physiol 1987;38:141-53.

27. Smith GP, Gooding MJ. Models of wheat grain quality considering climate, cultivar and nitrogen effects. Agricultural and Forest Meteorology 1999;94:159-70.

28. Goldenhar LM, Schulte PA. Intervention research in occupational health and safety. J Occup Med 1994;36:763-75.

29. Goldenhar LM, Schulte PA. Methodological issues for intervention research in occupational health and safety. Am J Ind Med 1996;29:289-94.

30. Miller BG, Cherrie JW, Groat S, et al. Changes in workplace concentrations of airborne respirable fibres in the European ceramic fibre industry 1987 1996. Ann Occup Hyg 2007:51:501-7.

31. Burstyn I, Kromhout H, Kauppinen T, et al. Statistical modelling of the determinants of historical exposure to bitumen and polycyclic aromatic hydrocarbons among paving workers. Ann Occup Hyg 2000:44:43-56.

32. Symanski E, Chang CC, Chan W. Long-term trends in exposures to nickel aerosols. AlHAJ 2000;61:324-33.

33. Burstyn I, Kromhout H. Trends in inhalation exposure to hydrocarbons among commercial painters in The Netherlands. Scand J Work Environ Health 2002;28:429-38.

34. Schlunssen V, Jacobsen G, Erlandsen M, et al. Determinants of wood dust exposure in the Danish furniture industry-results from two cross-sectional studies 6 years apart. Ann Occup Hyg 2008;52:227-38.

35. Fransman W, Peelen S, Hilhorst $\mathbf{S}$, et al. A pooled analysis to study trends in exposure to antineoplastic drugs among nurses. Ann Occup Hyg 2007:51:231-9.

36. Jacobs J, Meijster T, Meijer E, et al. Wheat allergen exposure and the prevalence of work-related sensitisation and allergy. Allergy 2008;63:1597-1604.

37. Heederik D, Houba R. An exploratory quantitative risk assessment for high molecular weight sensitizers: wheat flour. Ann Occup Hyg 2001;45:175-85.

38. Houba R, Heederik DJ, Doekes G, et al. Exposure-sensitization relationship for alphaamylase allergens in the baking industry. Am J Respir Crit Care Med 1996;154:130-6.

39. Houba R, Heederik D, Kromhout H. Grouping strategies for exposure to inhalable dust, wheat allergens and alpha-amylase allergens in bakeries. Ann Occup Hyg 1997:41:287-96. 